\title{
Toward ranking interventions for Technological Innovation Systems via the concept of Leverage Points
}

\author{
Alco Kieft $^{\mathrm{a}, *}$, Robert Harmsen ${ }^{\mathrm{b}}$, Marko P. Hekkert ${ }^{\mathrm{a}}$

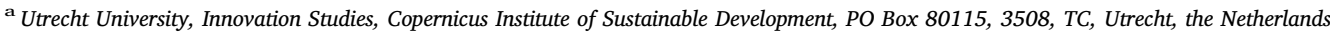 \\ ${ }^{\mathrm{b}}$ Utrecht University, Energy and Resources, Copernicus Institute of Sustainable Development, PO Box 80115, 3508, TC, Utrecht, the Netherlands
}

\section{A B S T R A C T}

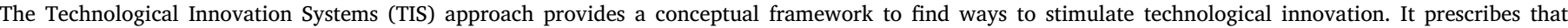

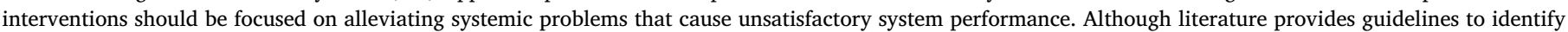

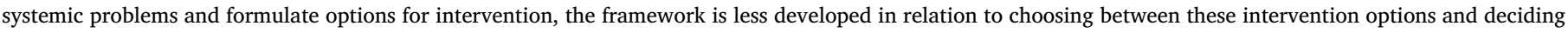

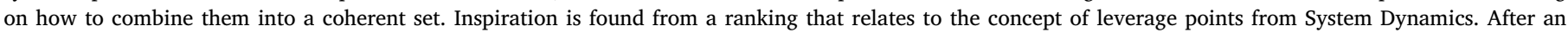

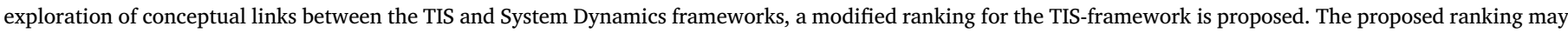

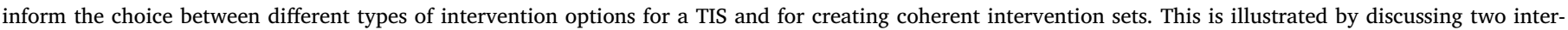
vention sets aimed to improve the energy-efficiency of existing houses in the Netherlands.

\section{Introduction}

The innovation systems approach rests on the notion that the speed and direction of innovation is strongly determined by the performance of the innovation system that forms around it. The approach has proven useful to derive intervention strategies for stimulating innovation not only in nations (Lundvall, 1992), sectors (Malerba, 2002), and regions (Cooke et al., 1997), but also in relation to specific technologies and technological domains (Bergek et al., 2008; Carlsson and Stankiewicz, 1991; Hekkert et al., 2007; Jacobsson and Jacobsson, 2014). As a framework, the Technological Innovation Systems (TIS) approach has become popular in both academic and policy circles.

As it is now, the output of an innovation system analysis is usually a list of systemic problems that need to be alleviated, accompanied with one or more intervention options for each identified problem. The analytical steps for performing a TIS-analysis up to this point are well documented (Bergek et al., 2008; Wieczorek and Hekkert, 2012). In addition, literature has presented categories of common types of problems (e.g. Chaminade and Edquist, 2010; Klein Woolthuis et al., 2005; Negro et al., 2012; Weber and Rohracher, 2012), and categories of intervention options that may serve as inspiration (e.g. Weber and Rohracher, 2012; Wieczorek and Hekkert, 2012). However, to date, little has been theorized about the follow-up activity of choosing between the formulated intervention options, or on combining them into an intervention set.

Although the challenge is clear (to select and combine the intervention options so that the impact on improving system performance is greatest) the uniqueness of each innovation system makes it difficult, if not impossible, to generalize about what impact different types of interventions have. As it is important to leave sufficient room for the particularities of each case, we instead pursue an understanding of the main considerations that play a role when choosing between (and combining) intervention options. Better knowing what to consider facilitates making such choices for particular innovation systems. For this, we find inspiration from system dynamics ideas (de Vries, 2013; Forrester, 1975; Meadows, 2008; Senge, 1990), specifically in a ranking associated to the concept of leverage points (Meadows, 1997, 1999, 2008).

An obvious similarity between the system dynamics and TIS frameworks is that both analyze complex systems consisting of interacting elements. ${ }^{1}$ More important, however, is that they both deal with how to achieve system change through intervention. To date, the usefulness of system dynamics for the TIS framework has been sought mainly in its modeling approach. For instance, Walrave and Raven (2016) created a system dynamics model of the emerging phases of a TIS to model its development in the context of four transition pathways. However, in addition to its high potential as a modeling approach, system dynamics is also rich in ideas on how to identify where to intervene for the

\footnotetext{
* Corresponding author.

E-mail addresses: a.c.kieft@uu.nl (A. Kieft), r.harmsen@uu.nl (R. Harmsen), m.p.hekkert@uu.nl (M.P. Hekkert).

1 In innovation systems literature, the terms "elements" (Klein Woolthuis et al., 2005; Markard et al., 2012; Wieczorek and Hekkert, 2012) and "components"

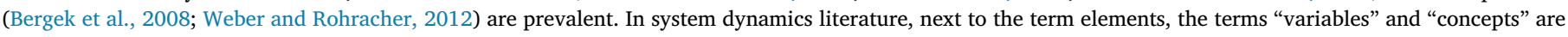
commonly used as synonyms (Forrester, 2009; Senge, 1990).
} 
Table 1

A ranking of places to intervene in complex systems according to system dynamics.

\begin{tabular}{|c|c|c|}
\hline Ranking & Place to intervene & Illustrative examples \\
\hline 1 & Paradigms & From only optimizing electricity production for (economic) efficiency, to also optimizing for climate change effects. \\
\hline 2 & Goals & From secure, stable and efficient electricity production, to secure, stable and low carbon electricity production. \\
\hline 3 & Self-organization & Allowing experimentation with the electricity law. \\
\hline 4 & Rules & Prioritizing renewable electricity on the grid over fossil-fuel based electricity. \\
\hline 5 & Information flows & Providing real-time information on renewable electricity production. \\
\hline 6 & Reinforcing feedback loops & Deflecting financial resources from fossil-fuel based technologies, to renewable electricity technologies. \\
\hline 7 & Balancing feedback loops & Decoupling of economic growth and energy-use, through end-use energy efficiency improvement. \\
\hline 8 & Material stock-and-flow structure & From a unidirectional electricity grid (central production), to a bidirectional electricity grid (decentralized production). \\
\hline 9 & Numbers & Reducing value-added tax for solar panels. \\
\hline
\end{tabular}

greatest impact. These ideas converge in the concept of leverage points (Meadows, 1997, 1999, 2008). Although leverage points have found its way into literature on transitions (Abson et al., 2016; Luederitz et al., 2017), its worth has not yet been explicitly explored in relation to the TIS framework.

A leverage point is a point in a particular system where a shift, "can produce big changes in everything" (Meadows, 1999, p. 1). In other words, an intervention on a leverage point has great potential transformational power. Meadows proposed a ranking based on her experience with modeling complex systems, which expresses where leverage points are increasingly often found (Meadows, 1997, 1999, 2008). The ranking should be seen not as, "a recipe for finding leverage points" but as, "an invitation to think more broadly about system change" (Meadows, 2008, p. 147). Since Meadows presented her ranking as tentative, we distill the main arguments that underlie positioning items on the ranking scale. We subsequently use these arguments to propose a ranking for Technological Innovation Systems. In this way, we answer the question whether and how the concept of leverage points concept from system dynamics and the associated ranking may inform choices between intervention options for a particular TIS. The proposed TIS ranking is our invitation to think more broadly about how to make TISs change.

The concept of leverage points and the associated ranking are first explained in further detail, leading to a stylized description of the reasoning behind the ranking distilled from Meadows' main arguments. Subsequently, after a reflection on conceptual differences between the TIS and system dynamics frameworks, we propose a ranking for the TIS framework. Next, this ranking is discussed in relation to two intervention sets that aim to stimulate renovation toward energy-efficient houses in the Netherlands. We end with a discussion of issues left open for further consideration.

\section{The ranking from system dynamics}

The items on the ranking from system dynamics relate - some more directly than others - to the main system dynamics concepts of feedback loops, stocks, flows, delays, paradigms, goals and rules. System dynamics as an approach strives to understand the often counterintuitive behavior of complex systems and, although systems are considered to consist of elements, the focus is thus placed mainly on how these elements interact through feedback loops. They are even considered more important than the elements themselves (Forrester, 1975). Feedback loops link together - usually multiple - stocks and flows. Stocks are 'accumulated stuff' and can take many forms (people, money, water, cars, trust etc.) and flows increase or decrease these stocks. For instance, if there is a shortage of skilled labor (stock), this may trigger additional training programs (feedback from stock to flow) leading to more skilled people entering the labor force (increased inflow). Feedback loops generally have inherent delays, for instance the time it takes to design the training programs and give the trainings. Moreover, how stocks and flows are connected in feedback loops depends on the paradigms that underlie the system, the system goals that guide action, and the rules in place.

This section works toward understanding the reasoning behind the ranking. Table 1 gives an overview of the ranking. ${ }^{2}$ Each item on the ranking will be introduced using examples from a system of unsustainable electricity production (fossil fuels) that is to change into a system of sustainable electricity production (renewables). ${ }^{3}$ For each item, the description ends with quotes reflecting Meadows' main arguments for the placement of items on the ranking. Based on these quotes, we present a stylized description of main factors determining the order of the ranking.

Paradigms form the first item on the ranking. Paradigms are, "the shared idea in the minds of society, the great big unstated assumptions [...] or deepest set of beliefs about how the world works." (Meadows, 2008, p. 162). For example, for decades, the electricity production system has been optimized mainly on efficiency, and then especially on cost-efficiency. The shift toward renewable electricity production is made possible by a paradigm change, namely that the electricity system must not only be optimized for efficiency, but also for environmental aspects. ${ }^{4}$ Paradigms are placed first on the ranking mainly because of their transformative power: "people who have managed to intervene in systems at the level of a paradigm have hit a leverage point that totally transforms systems." (Meadows, 1999, p. 18). However, Meadows also adds, "You could say paradigms are harder to change than anything else about a system, and therefore this item should be lowest on the list [...]. But there's nothing physical or expensive or even slow in the process of paradigm change. In a single individual, it can happen in a millisecond. [...] Whole societies are another matter. They resist challenges to their paradigms harder than they resist anything else." (p. 18).

System level goals form the second item on the ranking. These goals depend less on what actors in the system say, but more on what the system does. For an unsustainable electricity production system, economy of scale is a main system goal. This not only increases both energetic and economic efficiency but also leads to a centralized production system. Instead, for a sustainable electricity production system, the main goal changes to producing only low carbon electricity. This opens up possibilities for a decentralized production system, or to a combination of centralized and decentralized production. A system goal that both energy systems share is retaining energy security and grid stability. Meadows (2008) main argument for placing system goals high on the ranking is that if they change, "everything further down the list [...] will be twisted to conform to that goal" (p. 161).

\footnotetext{
2 This ranking is a combination of the rankings from Meadows, 1997, 1999 and 2008. It shows the nine leverage points as presented in Meadows, 1997, but uses the terminology from Meadows (1999) and (2008).

${ }^{3}$ We note that this is a complex case and we thus do not strive for completeness: our goal is limited to providing illustrative examples.

${ }^{4}$ We chose to exemplify this item with a relatively small paradigm change. A more extreme paradigm change would be electricity production being solely optimized for climate change effects.
} 
Self-organization reflects the ability of a system to adapt and evolve and requires, "marvelously clever rules" that, "govern how, where, and what the system can add onto or subtract from itself under what conditions" (Meadows, 2008, p. 159). For instance, in the Netherlands, smart-grid projects were inhibited by a strict electricity law for years, after which twenty smart-grid projects were allowed room for experimentation. According to Meadows: "The intervention point here is obvious, but unpopular. Encouraging variability and experimentation and diversity means 'losing control'. [...] Who wants that?" (Meadows, 2008, p. 160).

The content of rules is next. Some rules are absolute (e.g. physical laws), whereas, "Laws, punishments, incentives, and informal social agreements are progressively weaker rules." (Meadows, 2008, p. 158). In relation to the illustrative case, changing the electricity law to prioritize renewable electricity on the grid and voluntary covenants in which actors commit to produce renewable electricity provide examples. Meadows mentions that, "Power over the rules is real power. That's why lobbyists congregate when Congress writes laws $[\ldots]$ " (Meadows, 1999, p. 14).

Information flows determine who in the system has - and who does not have - access to information. Information flows are important because they often lead to additional feedback in the system. For instance, providing real-time information about locally produced solar electricity to households may stimulate the use of renewable electricity when it is available (thus contributing to the goal of grid stability). However, intervening on information flows often leads to resistance: "Adding or restoring information can be a powerful intervention, usually much easier and cheaper than rebuilding physical infrastructure, $[\ldots]$ if you can get the power that be permit it to happen (or go around them and make it happen anyway)." (Meadows, 2008, p. 157).

The next two items on the ranking both relate to changing specific types of already existing feedback loops. Reinforcing feedback loops lead to exponential growth or - in reverse - to exponential decline. For instance, fossil-fuel based technologies have long gained large investments, stimulating their use, leading to profits, leading to more investments. Deflecting financial resources from fossil-fuel based technologies to renewable energy technologies may weaken the reinforcing feedback loop that stimulates the former and strengthens the one that stimulates the latter. A balancing feedback loop counteracts the negative effects of a reinforcing feedback loop, for instance, improvement of energy efficiency or technological innovation may counteract the additional $\mathrm{CO}_{2}$ emissions that result from economic growth (decoupling). What is more, most feedback loops have inherent delays that often lead to unwanted system fluctuations. For instance, the long lead times of energy production projects in combination with cycles of economic growth and decline create periods of overproduction and underproduction. Meadows mentions that she, "would list delay length as a high leverage point, except for the fact that delays are not often easily changeable. Things take as long as they take. [...] But if there is a delay in your system that can be changed, changing it can have big effects" (Meadows, 1999, p. 9). In addition, "It is usually easier to slow down the change rate, so that inevitable feedback delays won't cause so much trouble. That's why growth rates [reinforcing feedback loops] are higher up on the leverage-point list than delay times." (Meadows, 2008, p. 152).

The next item on the ranking - material stock-and-flow structure represents the physical parts of the system. For instance, shifting to renewable energy goes hand in hand with further electrification of the energy supply and requires a stronger electricity grid. Making changes to physical infrastructure, "can have an enormous effect on how the system operates" (Meadows, 2008, p. 150-151), "but is rarely a leverage point, because changing it is rarely quick or simple." (Meadows, 2008, p. 151).

Finally, numbers are parameters that determine the size of flows through the system. If a number changes, the basic structure of elements and feedback loops stays the same. For example, reducing the value-added tax on solar panels changes little in which actors are involved, what their responsibilities are, what kind of information they receive, etcetera. Although this may improve the payback time of solar panels and make some additional homeowners willing to invest, it does not persuade homeowners that do not like their aesthetics (paradigm), or support homeowners that are not allowed to install solar panels because their house is located in a historic district (rules). Although intervening on numbers is often easy, Meadows mentions that intervening on numbers is, "Diddling with the details, arranging the deck chairs on the Titanic" (Meadows, 2008, p. 148).

The quotes given above reflect three main factors in the argumentation behind the relative position of items on the ranking. First of all, items are considered to differ in their potential to change a system. This is most clearly seen in comparing the highest and lowest item: paradigm changes may 'totally transform systems', whereas a number change is 'diddling with the details'. We will call this first factor the system change potential. However, additional factors must be at play since some items (e.g. material stock-and-flow structures) are placed low on the ranking even though their potential for system change is considered to be high. These additional factors relate to implementation difficulties in the form of physical constraints and resistance to change. Meadows mentions not only that intervening on material structures can have an enormous effect but also that changing it is rarely quick and simple. In addition, changing delays in feedback loops may have big effects but is also often difficult to change. Since the given arguments refer mainly to physical difficulties, we will call this second factor physical constraints. Next to this, Meadows' arguments point to actor resistance. This is reflected in the arguments that adding information flows only has transformational power if the powers that be permit it to happen, and in calling intervening on self-organization unpopular and comparing it to losing control. In general, "The higher the leverage point, the more the system will resist changing it." (Meadows, 2008, p. 165). We call this third factor resistance to change.

Meadows argues that intervening in a certain place in a complex system only has transformational power (only is a possible leverage point) when the system change potential of the place in the system where the intervention acts upon is high enough and both physical constraints and resistance to change can be overcome. Since systems consist of similar elements (see next section), and system change potential is mainly a characteristic of the place in the system where the intervention acts upon, the system change potential of different types of intervention options is largely independent of the particular system under study. However, the extent of physical constraints and/or resistance to change depends more on the specificities of the system under study, together making that different systems have different leverage points. The ranking represents that leverage points are increasingly often found from bottom to top.

Fig. 1 provides a stylized graphical depiction of how the three factors (system change potential, resistance to change and physical constraints) together determine whether an intervention option is a possible leverage point for a particular system. For instance, an internet campaign that informs the general public about sustainable technologies acts upon information flows. Information flows have substantial but not major system change potential (e.g. paradigms and goals have more system change potential). Now, whether an internet campaign will reach its substantial potential depends first of all on whether physical constraints can be overcome. In many countries this will not form a bottleneck since fast and reliable internet is available, but for specific countries or regions the quality of the internet infrastructure may form a bottleneck. In addition, resistance to change from system actors must be overcome. For an internet campaign this is for instance easier if the propagated message reflects the shared vision of system actors. In other words, whether an internet campaign that pushes sustainable technologies is a leverage point is system specific. In Fig. 1, the larger the volume of the formed cube (determined by how far each factor is away from the origin), the higher Meadows considers the 


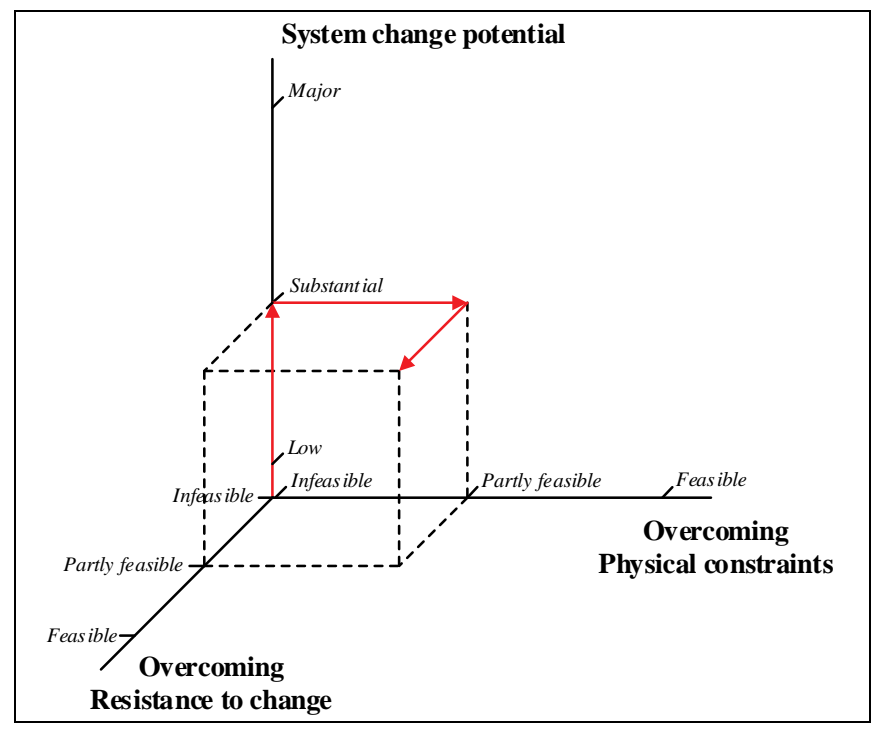

Fig. 1. Graphical depiction of three main factors that (according to Meadows) determine whether an intervention option is a leverage point for a particular system.

transformational power of a particular intervention to be. This means that, for a particular system, the intervention options with large cube volumes represent possible leverage points. The ranking represents that leverage points are (much) more often found in the top of the ranking than at the bottom.

\section{Conceptual fit between technological innovation systems and system dynamics}

In this section we reflect on conceptual differences between the TIS and System Dynamics frameworks, focusing on the following: (1) differences in terminology used by both frameworks to describe a system and its dynamics; (2) whether a leading role for ideas over material structures fits the TIS-framework; (3) whether having paradigms as separate item on the ranking is appropriate for TISs; (4) the transformational power of single interventions; and (5) differences in how system boundaries are set.

First, compared to system dynamics, the TIS framework uses different terminology for system elements and to describe dynamics. Literature on innovation systems generally considers actors, interactions between these actors and institutions as the main elements. For institutions, it is common to distinguish between formal institutions laid down in legislation and regulation, and informal institutions such as culture, paradigms, norms and values. In addition, infrastructure which can be divided into knowledge, financial and physical infrastructure - is commonly considered a structural element (Wieczorek and Hekkert, 2012) and the same applies to technology (e.g. in Jacobsson and Bergek, 2011; Jacobsson and Jacobsson, 2014; Markard and Truffer, 2008). In addition to the system structure, the TIS-framework emphasizes key processes, often called functions (Bergek et al., 2008; Hekkert et al., 2007). Structure and functions are two sides of the same coin as functions are made possible by the system structure. Dynamics in an innovation are usually described using feedback loops between these key processes (Negro et al., 2008; Suurs and Hekkert, 2009). Although the existence of feedback between structural elements is unquestioned in TIS-literature, this is only rarely made explicit during a TIS-analysis (Kieft et al., 2017). The above should make clear that, although the system dynamics framework has sufficient overlap with the TIS-framework to be used for inspiration, conceptual differences make re-interpretation and adaptation of the ranking necessary.

Second, the ranking is partly built on the idea that changes in higher items lead to changes in lower items but not vice versa, which is the result of an implicitly more idealistic view on reality. For instance, Meadows (2008) mentions not only that if goals change, "everything further down the list [...] will be twisted to conform to that goal" (p. 161) but also that, "Paradigms are the sources of systems. From them [...] come system goals and information flows, feedbacks, stocks, flows, and everything else [...]" (p. 163). As these higher ranked items are more 'idea-like' (paradigms, goals, rules) compared to lower ranked items (and then especially material-stock-and-flow-structure), the ranking reflects a certain tendency to favor ideas over material structures. ${ }^{5}$ In other words, the direction of causality runs from ideas to the more material structures. Since literature on both system dynamics and TIS commonly takes a more dualistic view where ideas and material structures both enable and constrain each other without a principle direction of causality, this raises the question whether a more idealistic view fits well with the TIS framework. We found that not only TIS literature but also literature on technological change more broadly, provides numerous examples of authors that (implicitly) take an idealistic view. A first indication comes from TIS-literature. Even though there is broad consensus that institutions - which include norms, values and paradigms - form a central structural element in any innovation system, there is no consensus on the role of physical infrastructures. Wieczorek and Hekkert (2012) state: "Infrastructure does not have a steady position as a structural element of innovation systems and there is no conclusive agreement in the key literature as to what the term infrastructure covers." (p. 77). Where some authors mention physical infrastructures explicitly (e.g. Klein Woolthuis et al., 2005), others do not mention it at all (e.g. Jacobsson and Johnson, 2000). In addition, literature on expectations in relation to technological change also does not shy away from a more idealistic view. Borup et al. (2006) for instance mention that, "expectations can be seen to be fundamentally 'generative' [...]” (p. 285), and the work by van Lente and Rip (1998) on prospective structures argues that actor expectations about future structures shape decisions that change real structures (Budde et al., 2012). As we are not alone in empathizing with a more idealistic view, we will largely stay true to the order of the ranking as proposed by Meadows. However, we deviate from the idea that intervening higher on the ranking automatically leads to changes in lower ranges of the ranking. Instead, we suppose that 'lower' interventions offer support, and are often even necessary, for achieving the potential of the intervention on the highest ranking item. In later sections, this supportive role of interventions in a larger intervention set is further explored and exemplified.

Third, positioning paradigms as separate item on a TIS-ranking is problematic. To begin with, Meadows gives paradigms a prominent position not only because the impact of a paradigm change may be great, but also because it is sometimes relatively easy to achieve. ${ }^{6} \mathrm{Al}-$ though this can be imagined for smaller systems like a company that changes its manager, for paradigms shared within a community, society, or TIS, this is much more difficult. Meadows (2008) also implies that for more complex systems this could justify a position lowest on the ranking. ${ }^{7}$ In addition, Meadows exemplifies the large potential impact of paradigm change by pointing at high-level paradigms like capitalism or democracy. However, while a change in such paradigms may affect technological change processes, it seems far-fetched to strive for such paradigm changes if stimulating technological innovation is the pursuit.

\footnotetext{
${ }^{5}$ Meadows quotes Emerson to make this point: "[...] the least enlargement of ideas ... would cause the most striking changes of external things" (p. 163).

6 "There's nothing physical or expensive or even slow in the process of paradigm change. In a single individual it can happen in a millisecond." (Meadows, 2008, p. 163-164).

7 "You could say paradigms are harder to change than anything else about a system, and therefore this item should be lowest on the list" and "Whole societies are another matter - they resist challenges to their paradigms harder than they resist anything else." (Meadows, 2008, p. 163-164).
} 
Table 2

A ranking of interventions for TISs, and related concepts from the system dynamics ranking.

\begin{tabular}{|c|c|c|}
\hline Ranking of interventions for TISs & Description & $\begin{array}{l}\text { Related concepts from system dynamics } \\
\text { ranking }\end{array}$ \\
\hline 1. Directionality & $\begin{array}{c}\text { Collective direction of actor goals }+ \text { informal institutions (paradigms, worldviews, norms, } \\
\text { values) that shape these goals. }\end{array}$ & Goals, Paradigms \\
\hline 2. Institutions & Structural element institutions (generally formal institutions) & Self-organization, Rules \\
\hline 3. Information flows & $\begin{array}{c}\text { Interventions that increase information flows (i.e. structural elements actors, knowledge } \\
\text { infrastructure, physical infrastructure) }\end{array}$ & Information flows \\
\hline 4. Feedback loops & Feedback loops in system structure or between functions, and their delays & $\begin{array}{l}\text { Reinforcing feedback loops }+ \\
\text { Balancing feedback loops }\end{array}$ \\
\hline 5. Physical infrastructure & Structural element physical infrastructure & Material stock-and-flow structure \\
\hline 6. Augmentations & Slightly strengthen, improve or increase already existing structural elements and links & Numbers \\
\hline
\end{tabular}

In other words, the high-level paradigms that Meadows points to are generally out of scope. A final reason to interpret paradigms differently for TISs is that paradigms are difficult to consider separate from the TIS structural elements. For instance, older paradigms may be 'fixed' in current physical infrastructure ${ }^{8}$ or they can be considered informal institutions that shape actor goals. For these reasons, paradigms do not come back as separate item on the TIS-ranking but are discussed in relation to other items.

Fourth, Meadows goes so far as comparing leverage points with 'the silver bullet, miracle cure or secret passage' (Meadows, 1999, p1), reflecting great confidence in the ability of a single intervention to transform a system. However, in both system dynamics literature more broadly and sustainability transitions literature specifically, it is common to talk about multiple leverage points that together hold transformational power (e.g. Abson et al., 2016; Luederitz et al., 2017). The TIS-framework also prescribes that weak system performance usually arises from a multitude of insufficiencies in system elements. Great confidence in single interventions also seems problematic in light of the rebound effect: if interventions are often negated by reactions elsewhere in the system, this implies a necessity to intervene in multiple places at once. Even Meadows (2008) herself mentions multiple interventions to get out of common system traps. Therefore, to make a complex system (like a TIS) change, we deem an intervention set that pushes on multiple places simultaneously necessary.

Fifth, system dynamics and the TIS-framework think differently about system boundaries. System dynamics takes a so-called 'endogenous' point-of-view, which means that causes for system behavior are always contained within the structure of the system itself. The consequence is that interventions, by definition, always target the internal system structure. Contrasting this, the TIS-framework makes the distinction between the system and its context (Bergek et al., 2015). Problems that inhibit a TIS may thus exist both inside and outside the system boundaries (Bergek et al., 2008; Meelen and Farla, 2013) and the same applies for interventions. In relation to the ranking this means that, for lean TIS delineations, more of the items on the ranking fall outside of the TIS. To assure that sufficient examples are available to exemplify the items on the TIS-ranking, we will therefore make use of an illustrative case study of a TIS with a rather broad system delineation.

\section{A ranking of interventions for Technological Innovation Systems}

In this section, we propose a ranking of interventions for technological innovation systems for which we interpret the items from the system dynamics ranking from the perspective of the TIS theoretical framework. Table 2 gives an overview of the TIS-ranking (column 1 and

\footnotetext{
${ }^{8}$ For instance, what size a house should be (older houses are in the Netherlands on average much smaller compared to newer houses).
}

2) and shows how each item relates to the system dynamics ranking (column 3).

The rest of this section will discuss each item on the TIS-ranking one-by-one, thereby using examples from the empirical domain of renovating houses toward energy-efficiency, or in short, the renovation TIS. Although most examples apply to any country, some are specific to the Netherlands. We interpret this system to be a TIS around the competence bloc (Carlsson et al., 2002) of technologies necessary to renovate toward energy-efficient homes, which is embedded in the traditional construction sector and in turn in a national system. We intentionally chose a broadly delineated TIS, to make sure that the empirical domain provides examples for all items on the ranking.

The TIS-ranking starts with interventions that affect its directionality (Weber and Rohracher, 2012), which is related to the goals and paradigm concepts from system dynamics. Directionality is an emergent system property, which means that - although not all actor goals are necessarily aligned - they do collectively point into a certain direction. ${ }^{9}$ The goals that actors pursue are shaped by informal institutions like worldviews, norms, values etcetera. Intervening on the directionality may therefore involve a collective reflection process, during which actors reflect on their beliefs and align their goals to a collective - often societal - goal. In the renovation TIS, this would mean convincing actors to set ambitious goals regarding the reduction of energy-use of their housing stock, which would stimulate the implementation of energy-efficiency (e.g. insulation) and energy-production technologies (e.g. solar energy). There are no physical constraints that stand in the way of a directionality shift, but the resistance that can be expected is proportionate to the extent of directionality change proposed. Although a big change in system directionality may dramatically improve system performance, resistance is often substantial, making intervening challenging or something for the longer term.

Second on the TIS-ranking are institutions, which relates to the rules, and self-organization concepts from system dynamics. To facilitate further development and implementation of a technology, new institutions (rules) may have to be designed, or outdated ones that have turned into bottlenecks may have to be adapted. Such 'rules of the game' are generally formalized in laws, procedures, standards or codes of conduct. In addition, not only the content of such institutions matters but also the room they provide for technological change (self-organization). This may be achieved by periodically monitoring policies and adapting them if needed, or by using portfolio approaches instead of focusing on single technological options. ${ }^{10}$ An institutions-related intervention from the renovation TIS concerns changing the Dutch

\footnotetext{
${ }^{9}$ A Technological Innovation System has no goal in itself. In earlier TIS-literature, TISs were seen as having goals (see e.g. Bergek et al., 2008), but this view has become less prominent after the attention for agency increased (Farla et al., 2012; Markard et al., 2012).

${ }^{10}$ These examples come from Weber and Rohracher (2012), in which these are mentioned as examples for increasing system Reflexivity, which is a quite similar concept to Self-Organization from Systems Thinking.
} 
electricity law. The electricity law was created with centralized electricity production in mind and does not facilitate small scale energy production on houses. ${ }^{11}$ Although an intervention on institutions may have a major impact on improving the performance of this TIS, the degree of freedom for intervening on the electricity law is limited by the system directionality. For instance, proposing far reaching adaptations to the electricity law (e.g. proposing to only allow renewable energy technologies to be connected to the grid) that are not in line with the current system directionality are unlikely to be accepted. Even though there are no physical constraints that inhibit a law change, vested actors may resist intervening here. Difficulties to change the electricity law in the Netherlands reflect this. ${ }^{12}$ Although intervening on institutions may be powerful and there are no physical constraints, resistance to change is often high.

Information flows are vital in any innovation system and there are often many possibilities to add information flows. However, implementation difficulties in the form of physical constraints or resistance to change are sometimes present, and the intervention's impact is restricted by higher ranked items. An example specific to the renovation TIS can be found in the type of guarantees given by installation companies. For decades, guarantees were only provided on installed products and the installation work, and not on the actual energy savings. Providing guarantees on energy savings requires an additional information flow between energy-use data and installation companies. For such intervention there may be some physical constraints to overcome (e.g. in communication infrastructure), and resistance can be expected from installation companies that have to incorporate energy performance guarantees into their routines. In addition, even if performance guarantees are successfully implemented, it would not drastically improve the performance of this TIS as long as the electricity law does not allow local energy production (institutions) or the directionality of the TIS is not geared toward sustainability. At the same time, however, performance guarantees may stimulate general awareness of sustainability issues and in this way, support directionality change and adaptations to the electricity law. Adding an information flow generally has less effect on changing a system compared to higher ranked items, but it may play an important supporting role.

Feedback loops are also in innovation systems manifold (Carlsson et al., 2002; Chaminade and Edquist, 2010; Edquist and Johnson, 1997; Jacobsson and Jacobsson, 2014; Markard and Truffer, 2008; Wieczorek and Hekkert, 2012). For emerging TISs specifically, literature has identified desirable reinforcing feedback loops that contribute to system build-up, called 'motors of innovation' (Negro et al., 2008; Suurs and Hekkert, 2009). Intervening on feedback loops in a TIS thus - on the one hand - means strengthening such desirable reinforcing feedback loops and - on the other hand - weakening balancing feedback loops that slow them down. Next to feedback loops between key processes, there are also often possibilities to add/strengthen feedback between structural elements. For instance, making rent height dependent on energyefficiency may stimulate housing associations to renovate their houses in this direction. In relation to delays, the challenge lies - from a TISperspective - mainly in reducing them as much as possible, although this is often physically difficult. For instance, how do you speed up the delay between providing a research grant and having research results, between setting up trainings and having a trained workforce, or between planning a new pilot project and finishing it? Indeed, feedback loops are only useful if they push the system toward the desired

\footnotetext{
${ }^{11}$ A specific example is people that annually produce net surplus electricity with their solar panels who cannot supply this to their neighbors because they then become a 'supplier' by law and need to adhere to unrealistically high financial and organizational requirements. In practice, this means that they have to sell their excess electricity to their energy supplier for a low price.

${ }^{12}$ An adaptation to the energy law called STROOM, was voted down on 22 December 2015 (Eerste Kamer, 2015).
}

direction, and the possibility of strengthening, adding or speeding up feedback loops is only possible if allowed (institutions). Intervening on feedback loops is not always easy, but plays an important role in any intervention set.

The physical infrastructure of an innovation system relates to the concept of material stock-and-flow structure from system dynamics. The buildup, or change in direction, of a TIS often requires phasing out the old and the construction of new infrastructures. However, this does not mean that intervening on the physical infrastructure will - by itself - have a large impact on improving system performance. A specific example from the renovation TIS is that most Dutch houses are using gas-fired boilers for heating and gas cooktops for cooking. Replacing these with solar panels and induction cooktops for cooking and heat pumps for heating requires strengthening the electricity grid, but strengthening the electricity grid will not make people buy heat pumps and induction cooktops. For this, additional changes are necessary in higher ranges of the ranking, for instance in the goals that people pursue or in the rules. In addition, intervening on physical infrastructure is not always realistic. For example, the basic structure of the existing housing stock, e.g. their orientation toward the sun, is difficult to change and thereby restrict options for refurbishment. Although such physical constraints can theoretically be overcome by demolishing the houses, this would first require fundamental shifts in items higher on the ranking.

The final item on the ranking is formed by augmentations; the equivalent of numbers in system dynamics terms. In relation to a TIS, we define an augmentation as an intervention that slightly increases or improves an already existing structural element or the links between elements. In other words, an augmentation does not involve the creation of new elements or new links between elements. Examples of augmentations in the renovation TIS are the National Energy Reduction Fund (in Dutch: energiebespaarfonds) and the ratio between the electricity and gas tax. The National Energy Reduction Fund issues cheap loans to homeowners for energy-efficiency measure and in this way, increases the available financial capital in the system. However, it is hardly being used. Regarding the tax example, although reducing the electricity tax against the gas tax may discourage the use of gas-based technologies and stimulate electric heat pumps, it also increases the payback time for e.g. solar panels. Similar to information flows and feedback loops, intervening on augmentations is not only limited by items higher on the ranking, but may also support changes at higher items on the ranking. The prospect of subsidies or the availability of the National Energy Reduction Fund may, for instance, provide a stimulus for actors to change their goals in line with the desired TIS directionality. Despite augmentations often being relatively easy to implement, intervening only on augmentations is unlikely to drastically improve a TIS' performance, yet they may support interventions higher in the ranking.

The above description, together with the earlier exploration of conceptual links between system dynamics and the TIS-framework, mirrors a number of key characteristics of the TIS-ranking. To begin with, the ranking suggests that the chances for improving system performance increase substantially for interventions from bottom to top, but only when these interventions are ambitious (e.g. a complete law reform has more change potential compared to a minor law amendment). At the same time, implementation difficulties - either in the form of resistance to change or physical constraints - are proportionate to the extent of change proposed and are thus often high for ambitious interventions (e.g. implementing a complete law reform is usually more difficult compared to implementing a minor law amendment). This gives two ways to reduce implementation difficulties of which the first is to lower ambition (but this is not desirable when substantially improving system performance is pursued). However, implementation difficulties are also reduced when interventions on lower items are designed to support the highest-ranking intervention. For instance, the prospect of subsidies (augmentations) in combination with an 
information campaign (information flows) may activate actors to rethink their goals (directionality). Thus, although interventions on lower items have little transformational power by themselves, they may have an important supportive role in an intervention set. Often, interventions on lower ranked items are not only beneficial, but even necessary to reach the potential of an intervention on a higher ranked item. For instance, even if all actors set ambitious goals regarding renovation toward energy-efficiency (directionality), little changes if making adaptations to existing houses is not allowed (institutions), or the houses themselves are not adapted (physical infrastructure). In other words, achieving impact requires a well-designed intervention set.

\section{Coherent intervention sets aiming for improving the energy performance of existing houses}

To exemplify the TIS-ranking further, we discuss two fundamentally different intervention sets that both aim to stimulate homeowners to renovate toward greater energy-efficiency in the Netherlands. ${ }^{13}$ The first intervention set is an extension of the traditional approach to renovation, whereas the second intervention set pushes for an alternative renovation approach around so-called renovation concepts. As the ranking will show, both intervention sets are coherent but also reflect a fundamentally different choice between system change potential and implementation difficulties.

The traditional approach to renovation is based on creating a specific renovation plan for each renovation project, which can be one house or multiple houses. Renovation companies traditionally specialize in a single or a couple of activities, e.g. roofing, windows or foundation. For a larger renovation, multiple measures are 'stacked' and subsequently installed by different companies. With the advent of renovation toward energy-efficiency, some companies added energy-efficiency (e.g. insulation) and energy-production measures (e.g. solar panels) to their existing product portfolio, and in addition, new specialized companies arose. The first intervention set strives to persuade homeowners and housing associations to install one or more energyefficiency and/or energy-production measures offered by these companies.

The energy label forms the main intervention in this intervention set. An energy label runs from label G (very inefficient) to label A + + (energy neutral) and each measure taken represents a certain increase of the energy label. The energy label provides homeowners with information about the energy-performance of their house and on the efficiency gains that may be achieved with certain measures. Multiple information campaigns have propagated the existence of the energy label. In addition, individual measures have been - and are - supported with subsidies, there are tax benefits for homeowners with solar panels ('net metering' in English and 'salderingsregeling' in Dutch), and it was recently made obligatory to have an up-to-date energy-label when selling a house.

With this intervention set, the directionality of the TIS remains largely the same, as the approach is an extension of the traditional approach of 'stacking' measures. Institutions are also not strongly targeted, for example, although an updated energy label was made obligatory on paper when selling a house, no fines have been issued for violations. Instead, with the energy label and information campaigns as central interventions, this intervention set places the emphasis on adding information flows to the innovation system. What is more, there is no intervention on feedback loops and this approach strives to change the physical infrastructure as little as possible. The latter is signified by more efficient gas-fired boilers and blow-in wall insulation being the

\footnotetext{
13 This section is based on two research projects that made use of the TISframework (Kieft et al., 2015; Kieft and Harmsen, 2015). In addition, a more detailed description of the two renovation approaches can be found in Chapter 3 of Kieft (2017).
}

most common energy-efficiency measures, which both focus on reducing gas-usage instead of replacing gas for electricity. This intervention set is coherent as lower ranking interventions support the highestranking intervention (subsidies, tax-benefits and information campaigns all support label step renovations). However, it does not reach the higher ranges of the ranking and is not that radical in its approach. This is also reflected in the impact of this intervention set. Renovations toward energy-efficiency according to this approach are often implemented but usually involve only a small label step increase. For instance, many homeowners take one or a couple of label steps, whereas large scale renovation to a high energy label (A or higher) is rare. In other words, with the choice for this intervention set, ease of implementation was deemed more essential than system change potential.

Renovation concepts provide an alternative and upcoming approach for house renovation toward energy-efficiency. A renovation concept is a standardized methodology for renovating a particular type of house (e.g. a particular type of row house or flat building). Most renovation concepts are geared to the ambitious goal of reaching zero-on-the-meter (in Dutch: nul-op-de-meter), which means that annually energy production equals the energy-use of an average family. Instead of stacking measures, a renovation concept integrates multiple measures into a single proposition, e.g. a heat pump integrated in an insulated roof. Renovation activities are not performed on site, but construction components are prefabricated in a factory after which the house is stripped and the prefab components are installed in a matter of days. In addition, most renovation concepts are all-electric, which means that the house is no longer connected to the gas infrastructure after renovation. The use of renovation concepts directly challenges the traditional renovation approach based on stacking measures.

To stimulate renovation concepts, in collaboration with the Dutch renovation acceleration covenant (Stroomversnelling, 2013), another set of interventions is utilized. The covenant actively tries to persuade construction companies, housing associations and other stakeholders to strive for the goal of renovation toward zero-on-the-meter, which would mean a fundamental shift in renovation approach (change of directionality). In addition, to stimulate the development and uptake of renovation concepts, the covenant actors are lobbying for fundamental adaptations to the electricity law and the building code to facilitate their uptake (intervention on institutions). Developers of renovation concepts are obliged to provide an energy performance guarantee (which depends on an additional information flow of energy-use data to the concept developers), and - in a planned reform of the electricity law - the rent is allowed to increase more after a zero-on-the-meter renovation compared to after a label step renovation (feedback loop in favor of renovation concepts). Furthermore, the use of prefabricated construction components reduces the renovation activities on-site, and the gas connection of the house is removed (interventions on physical infrastructure). Finally, maximum mortgage possibilities have been extended for zero-on-the-meter houses (supportive augmentation). This intervention set reaches the higher range of the ranking and is ambitious in its approach. It is also coherent as lower ranking interventions support the highest-ranking intervention (all lower ranking interventions support a directionality change toward zero-on-the-meter renovations). By radically breaking with the more traditional approach to renovation it has the potential to change the directionality of this innovation system, yet implementation difficulties have been more severe than anticipated. To illustrate, the covenant focusing on housing associations is no longer on track to reach the goal of renovating 111,000 houses in 2020, and the covenant focusing on homeowners was cancelled after disappointing results. However, in a new policy program for the Dutch building sector (in Dutch: Bouwagenda), emphasis was again placed on renovation concepts. It is too early to tell whether this additional push will prove successful. In other words, with the choice for this intervention set, system change potential was deemed more essential than ease of implementation. 


\section{Discussion}

We reflect upon (1) the consequence of transferring a line of reasoning from System dynamics to TIS, (2) the factors that determine whether implementation difficulties can be overcome, (3) how feedback mechanisms within a TIS can be determined, and (4) using the ranking for less broadly delineated technological innovation systems.

First, the consequence of taking concepts from system dynamics as a starting point is that TIS-concepts that have no equivalent in system dynamics were unused. For example, TIS-literature describes that it is possible to intervene on the attributes of structural elements (Wieczorek and Hekkert, 2012), and technological change itself also impacts the TIS. Additionally, this paper gave limited attention to the key processes or functions of innovation systems, although they are a prominent TISconcept (Bergek et al., 2008; Hekkert et al., 2007). It should be possible to extend the reasoning in this paper to the functional level. It implies that the trade-off between potential impact on improving system performance and ease of implementation not only plays out differently for different types of interventions, but also for system functions. How these TIS-concepts fit within the TIS-ranking can be further explored.

Second, the system dynamics ranking (and consequently the TISranking) does not explain in what situations it is feasible to overcome implementation difficulties associated with a particular intervention option and when it is not. This is left to the analyst to judge, which is also unavoidable since each case has its own particularities. Factors that may influence this feasibility are the range of influence of the intervening actors - and related - their political and/or economic power, the willingness of these intervenors to put in extra effort if resistance is fierce, their capacity to counteract this resistance, and the timeframe that the intervenors have available for implementing the intervention (e.g. term of office length). One, or multiple, of these factors are probably responsible for the so far disappointing results of renovation concepts. How such factors influence whether intervening high in the ranking is feasible is left for further consideration.

Third, intervening on feedback loops in a TIS requires insight into the feedback loops at play. This insight can, for instance, be created by making explicit how systemic problems interact and form blocking mechanisms (Kieft et al., 2017). Or, the feedback loops between key processes can be made explicit using methods from literature on motors of innovation (e.g. Suurs, 2009). Additionally, group modeling approaches offer potential (Vennix, 1996). The group modeling approach has already proven its worth for capturing sustainability transition dynamics more broadly (de Gooyert et al., 2016) and we expect it will also prove favorable for capturing dynamics in technological innovation systems.

Fourth, for less broadly delineated systems analysts may find that some items do not fall within the TIS boundaries. For example, the electricity grid or the electricity law can be argued to fall outside of the boundaries of a heat pump or solar panel system. This makes it important - especially for less broadly delineated TISs - to consider the possibility of intervening in the context, underlining the necessity of the recently revived attention to TIS context (Bergek et al., 2015).

\section{Concluding remarks}

This paper started with the observation that the technological innovation systems theoretical framework currently does not provide the means to inform choices between intervention options. The challenge is to select and combine interventions so that the impact on improving system performance is highest. An increased understanding was pursued of the main considerations that play a role when selecting and combining intervention options for this purpose. Inspiration was found in ideas from system dynamics, specifically in the concept of leverage points and an associated ranking. After an exploration of conceptual links between the TIS and System Dynamics frameworks, a ranking of interventions that fits the TIS-framework was proposed. According to this ranking, most impact can be achieved by ambitiously targeting the highest-ranking still feasible intervention, and by supporting this main intervention with lower-ranked interventions. The TIS-ranking is our answer to the question whether and how the concept of leverage points from system dynamics and the associated ranking may inform choices between intervention options for particular technological innovation systems. The proposed TIS-ranking was subsequently discussed in relation to two intervention sets that aim to stimulate renovation toward energy-efficient houses in the Netherlands, showing that the ranking leads to a better understanding of the considerations that underlie these intervention sets. We hope that this paper provokes a broader discussion on how to make technological innovation systems change, and that thereby our combined understanding of how to choose between intervention options and combine them into intervention sets will improve.

\section{References}

Abson, D.J., Fischer, J., Leventon, J., Newig, J., Schomerus, T., Vilsmaier, U., von Wehrden, H., Abernethy, P., Ives, C.D., Jager, N.W., Lang, D.J., 2016. Leverage points for sustainability. Ambio 46 (1), 30-39.

Bergek, A., Jacobsson, S., Carlsson, B., Lindmark, S., Rickne, A., 2008. Analyzing the functional dynamics of technological innovation systems: a scheme of analysis. Res. Policy 37 (3), 407-429. https://doi.org/10.1016/j.respol.2007.12.003.

Bergek, A., Hekkert, M., Jacobsson, S., Markard, J., Sandén, B., Truffer, B., 2015. Technological innovation systems in contexts: conceptualizing contextual structures and interaction dynamics. Environ. Innov. Soc. Trans. 16, 51-64. https://doi.org/10 1016/j.eist.2015.07.003.

Borup, M., Brown, N., Konrad, K., Van Lente, H., 2006. The sociology of expectations in science and technology. Tech. Anal. Strat. Manag. 18 (3-4), 285-298. https://doi. org/10.1080/09537320600777002.

Budde, B., Alkemade, F., Weber, K.M., 2012. Expectations as a key to understanding actor strategies in the field of fuel cell and hydrogen vehicles. Technol. Forecast. Soc. Chang. 79 (6), 1072-1083. https://doi.org/10.1016/j.techfore.2011.12.012.

Carlsson, B., Stankiewicz, R., 1991. On the nature, function, and composition of technological systems. J. Evol. Econ. 1 (2), 93-118.

Carlsson, B., Jacobsson, S., Holmen, M., Rickne, A., 2002. Innovation systems: analytical and methodological issues. Res. Policy 31 (2), 233-245. https://doi.org/10.1016/ s0048-7333(01)00138-x.

Chaminade, C., Edquist, C., 2010. Rationales for public policy intervention in the innovation process: a systems of innovation approach. In: Smits, R., Kuhlmann, S., Shapira, P. (Eds.), Theory and Practice of Innovation Policy, an International Research Handbook. Edward Elgar, Cheltenham, U.K., pp. 95-114.

Cooke, P., Uranga, M.G., Etxebarria, G., 1997. Regional innovation systems: institutional and organisational dimensions. Res. Policy 26 (4), 475-491. https://doi.org/10. 1016/S0048-7333(97)00025-5.

de Gooyert, V., Rouwette, E., van Kranenburg, H., Freeman, E., van Breen, H., 2016. Sustainability transition dynamics: towards overcoming policy resistance. Technol. Forecast. Soc. Chang. 111, 135-145. https://doi.org/10.1016/j.techfore.2016.06. 019.

de Vries, Bert J.M., 2013. Sustainability Science. Cambridge University Press, Cambridge.

Edquist, C., Johnson, B., 1997. Institutions and organizations in systems of innovation. In: Edquist, C. (Ed.), Systems of Innovation: Technologies, Institutions and Organizations. Pinter, London, U.K., pp. 41-63.

Farla, J., Markard, J., Raven, R., Coenen, L., 2012. Sustainability transitions in the making: a closer look at actors, strategies and resources. Technol. Forecast. Soc. Chang. 79 (6), 991-998. https://doi.org/10.1016/j.techfore.2012.02.001.

Forrester, J.W., 1975. Collected Papers of Jay W. Forrester. Wright-Allen Press, Cambridge, MA.

Forrester, J.W., 2009. Some Basic Concepts in System Dynamics (D-4894). Sloan School of Management, Massachusetts Institute of Technology, Cambridge, MA.

Hekkert, M.P., Suurs, R.A., Negro, S.O., Kuhlmann, S., Smits, R.E.H.M., 2007. Functions of innovation systems: a new approach for analysing technological change. Technol. Forecast. Soc. Chang. 74 (4), 413-432. https://doi.org/10.1016/j.techfore.2006.03. 002 .

Jacobsson, S., Bergek, A., 2011. Innovation system analyses and sustainability transitions: Contributions and suggestions for research. Environ. Innov. Soc. Trans. 1 (1), 41-57. https://doi.org/10.1016/j.eist.2011.04.006.

Jacobsson, T., Jacobsson, S., 2014. Conceptual confusion - an analysis of the meaning of concepts in technological innovation systems and sociological functionalism. Tech. Anal. Strat. Manag. 26 (7), 811-823. https://doi.org/10.1080/09537325.2014. 900171.

Jacobsson, S., Johnson, A., 2000. The diffusion of renewable energy technology: an analytical framework and key issues for research. Energy Policy 28 (9), 625-640. https://doi.org/10.1016/S0301-4215(00)00041-0.

Kamer, Eerste, 2015. Tweede Kamer der Staten-Generaal, vergaderjaar 2014-2015, Voorstel van wet houdende regels met betrekking tot de productie, het transport, de handel en de levering van elektriciteit en gas (34 199). In: Staatscourant (ISSN 0921-7371)

Kieft, A.C., 2017. Stimulating Technological Innovation: Problem Identification and Intervention Formulation With the Technological Innovation Systems Framework 
(Doctoral dissertation. Retrieved from). http://www.narcis.nl.

Kieft, A.C., Harmsen, R., 2015. Changing Times in the Dutch Renovation Sector: Installation Companies and SME Contractors Under Pressure. Copernicus Institute of Sustainable Development Retrieved from. https://www.uu.nl/en/files/20150304rapportrexelpdf.

Kieft, A.C., Harmsen, R., Wagener, P., 2015. Warmtepompen in de bestaande bouw in Nederland: een innovatiesysteemanalyse. Copernicus Institute of Sustainable Development, Dutch Heat Pump Association and Business Development Holland Retrieved from. http://www.bdho.nl/wp-content/uploads/2015/06/20150322Rapport_STEM-3.pdf.

Kieft, A., Harmsen, R., Hekkert, M.P., 2017. Interactions between systemic problems in innovation systems: the case of energy-efficient houses in the Netherlands. Environ. Innov. Soc. Trans. 24, 32-44. https://doi.org/10.1016/j.eist.2016.10.001.

Klein Woolthuis, R., Lankhuizen, M., Gilsing, V., 2005. A system failure framework for innovation policy design. Technovation 25 (6), 609-619. https://doi.org/10.1016/j technovation.2003.11.002.

Luederitz, C., Abson, D.J., Audet, R., Lang, D.J., 2017. Many pathways toward sustainability: Not conflict but co-learning between transition narratives. Sustain. Sci. 12 (3), 393-407. https://doi.org/10.1007/s11625-016-0414-0.

Lundvall, B.A., 1992. National Innovation System: Towards a Theory of Innovation and Interactive Learning. Pinter, London.

Malerba, F., 2002. Sectoral systems of innovation and production. Res. Policy 31 (2), 247-264. https://doi.org/10.1016/S0048-7333(01)00139-1.

Markard, J., Truffer, B., 2008. Technological innovation systems and the multi-level perspective: towards an integrated framework. Res. Policy 37 (4), 596-615. https:// doi.org/10.1016/j.respol.2008.01.004.

Markard, J., Raven, R., Truffer, B., 2012. Sustainability transitions: an emerging field of research and its prospects. Res. Policy 41 (6), 955-967. https://doi.org/10.1016/j. respol.2012.02.013.

Meadows, D., 1997. Places to intervene in a system. Whole Earth 91, 78-84.

Meadows, D., 1999. Leverage points. In: Places to Intervene in a System. The Sustainability Institute, Hartland, VT.

Meadows, D.H., 2008. In: Wright, D. (Ed.), Thinking in Systems: A Primer. Chelsea Green, White River Junction, VT.

Meelen, T., Farla, J., 2013. Towards an integrated framework for analysing sustainable innovation policy. Tech. Anal. Strat. Manag. 25 (8), 957-970. https://doi.org/10. 1080/09537325.2013.823146.

Negro, S.O., Suurs, R.A., Hekkert, M.P., 2008. The bumpy road of biomass gasification in the Netherlands: explaining the rise and fall of an emerging innovation system. Technol. Forecast. Soc. Chang. 75 (1), 57-77. https://doi.org/10.1016/j.techfore. 2006.08.006.

Negro, S.O., Alkemade, F., Hekkert, M.P., 2012. Why does renewable energy diffuse so slowly? A review of innovation system problems. Renew. Sust. Energ. Rev. 16 (6), 3836-3846. https://doi.org/10.1016/j.rser.2012.03.043.

Senge, P.M., 1990. The Fifth Discipline: The Art and Practice of the Learning Organization. Currency Doubleday, New York, NY.

Stroomversnelling, 2013. Convenant van partners in het netwerk van de
Stroomversnelling.

Suurs, R.A., 2009. Motors of Sustainable Innovation: Towards a Theory on the Dynamics of Technological Innovation Systems (Doctoral dissertation. Retrieved from). http:// www.narcis.nl.

Suurs, R.A., Hekkert, M.P., 2009. Cumulative causation in the formation of a technological innovation system: the case of biofuels in the Netherlands. Technol. Forecast. Soc. Chang. 76 (8), 1003-1020. https://doi.org/10.1016/j.techfore.2009.03.002.

van Lente, H., Rip, A., 1998. Expectations in Technological Developments: An Example of Prospective Structures to be Filled in by Agency. In: Disco, C., van der Meulen, B. (Eds.), Getting New Technologies Together: Studies in Making Sociotechnical Order. De Gruyter, Berlin, Germany, pp. 203-230. https://doi.org/10.1515/ 9783110810721.203.

Vennix, J.A., 1996. Group Model Building: Facilitating Team Learning Using System Dynamics. Wiley.

Walrave, B., Raven, R., 2016. Modelling the dynamics of technological innovation systems. Res. Policy 45 (9), 1833-1844. https://doi.org/10.1016/j.respol.2016.05.011.

Weber, K.M., Rohracher, H., 2012. Legitimizing research, technology and innovation policies for transformative change: combining insights from innovation systems and multi-level perspective in a comprehensive 'failures' framework. Res. Policy 41 (6), 1037-1047. https://doi.org/10.1016/j.respol.2011.10.015.

Wieczorek, A.J., Hekkert, M.P., 2012. Systemic instruments for systemic innovation problems: a framework for policy makers and innovation scholars. Sci. Public Policy 39 (1), 74-87. https://doi.org/10.1093/scipol/scr008.

Alco Kieft is researcher at the Innovation Studies group of Utrecht University. His research focuses on the identification of 'problems' in innovation systems and on the formulation of related system interventions. His case studies focus on energy efficient houses. Before starting as PhD-researcher, he worked as a consultant in the construction sector where he helped companies with their sustainability programs.

Robert Harmsen is assistant professor energy \& resources at the Copernicus Institute of Sustainable Development (UU Faculty of Geosciences). He teaches in the master program Sustainable Development. His research focuses on energy efficiency and renewable energy and then more specifically on related policy interactions, e.g. the link between energy resources policies and energy \& climate policies. He was also co-author of a number of papers on Technological Innovation Systems. Before joining Utrecht University, he worked a senior consultant for Ecofys, the Energy Research Center of the Netherlands (ECN) and Cogen Netherlands.

Marko P. Hekkert is director of the Copernicus Institute of Sustainable Development and head of Innovation Studies. He studies the dynamics of emerging technological fields. Most of his studies focus on technological fields that contribute to a more sustainable society like renewable energy technologies. Theoretically he aims to contribute to the innovation systems perspective by improving our knowledge how emerging innovation systems develop and what type of micro mechanisms (power, lobby, research, strategy, expectations, resources) determine the dynamics of innovation systems. 